\title{
O bom nem sempre é o justo: responsabilidade social para além dos domínios das empresas
}

Maria de Fátima Garbelini

- Doutora em Técnicas y Métodos Actuales en Información y Documentación pela Universidad de Murcia, Espanha

- Especialista em Comunicação Audiovisual pela Universidad Internacional Del Mar / Universidad de Murcia

- Professora do Programa de Mestrado em Comunicação e Cidadania, na linha de pesquisa Mídia e Cidadania, da Faculdade de Comunicação e Biblioteconomia da Universidade Federal de Goiás (UFG)

- Professora da Faculdade de Comunicação e Biblioteconomia da UFG

- mgarbelini@hotmail.com

Walderes Lima de Brito

- Mestrando em Comunicação, linha de pesquisa Mídia e Cidadania, pela UFG

- Especialista em Assessoria de Comunicação pela UFG

- Graduado em Comunicação Social, habilitação em Jornalismo, pela UFG

- Prestador de serviços à Petrobras Transporte S/A (Transpetro), desde 2002, como supervisor de um Programa de Relacionamento da empresa com as comunidades do entorno do Oleoduto São Paulo-Brasília

-waldbrito@uol.com.br 
O termo responsabilidade social empresarial se consolida progressivamente como parâmetro de avaliação do modelo de gestão de uma empresa, na sua totalidade, diferenciando-se de todo tipo de filantropia empresarial. Esse artigo apresenta a tendência de esse conceito evoluir mais uma vez, migrando da condição de assunto privado de uma empresa para a condição de tema de interesse público.

PALAVRAS-CHAVE: RESPONSABILIDADE SOCIAL • SUSTENTABILIDADE • INTERESSE PÚBLICO

\section{Abstract}

The term corporate social responsibility (CSR) is progressively consolidated as a parameter of evaluation of a company's management model, and differs from all kinds of corporate philanthropy. This article draws attention to the fact that this concept is evolving from a matter of private interest to one of public interest.

KEYWORDS: CORPORATE SOCIAL RESPONSIBILITY • SUSTAINABILITY • PUBLIC INTEREST

\section{Resumen}

El término responsabilidad social empresarial se consolida progresivamente como un parámetro de evaluación del modelo de gestión de una empresa, en su totalidad, diferenciándose de todo tipo de filantropía empresarial. Este artículo presenta la tendencia de este concepto a sufrir una nueva evolución, cambiando de la condición de asunto privado de una empresa a la de tema de interés público.

PALABRAS CLAVE: RESPONSABILIDAD SOCIAL • SOSTENIBILIDAD • INTERÉS PÚBLICO 


\section{Ética empresarial e moralidade pública}

A conduta das empresas está em franco processo de transformação, tendo que, em Apouco tempo e alta velocidade, incorporar e harmonizar novos, abundantes e complexos princípios a suas tradicionais rotinas de atuação. Um dos propulsores desse movimento é a sociedade civil, um agente que conjuga força e fraqueza na sua constituição caótica, que por um lado dificulta o direcionamento de suas causas, mas, por outro, também obstrui as intervenções domesticadoras do Estado e do mercado.

No contexto de exacerbado neoliberalismo deste início de século XXI, a sociedade civil se apresenta como ator qualificado para exigir prestações de contas (accountability) tanto da parte do setor político quanto do sistema econômico, como analisa Wilson da Costa Bueno:

"O consumidor do século XXI, a sociedade civil organizada, os movimentos sociais e mesmo grupos de interesse mobilizados, como os ambientalistas, não estão interessados em disponibilizar brechas para que empresas, públicas ou privadas, tomem decisões e implementem medidas que penalizem a comunidade ou mesmo setores especificos. Mais ainda: estão vigilantes e dispostos a exigir que, se isso ocorrer, elas sejam penal e moralmente responsabilizadas." (2007, p. 135)

A intolerância crescente da população em relação aos atos inadequados do setor produtivo já repercute nas esferas do Estado, gerando maior rigor dos agentes públicos legisladores e fiscalizadores. Tudo isso indica que o agir ético das empresas configurase como requisito inegociável e que tem ares de tendência, e não de modismo. A capacidade de responder adequadamente às demandas de cada parte interessada, nas suas particularidades, é um grande desafio e o que melhor exprime a natureza do controverso termo responsabilidade social empresarial, expressão que, talvez, melhor abrigue esse conjunto de debates, confrontos e buscas de definições.

De início, há duas questões-problema sobre o assunto ética nas empresas: como cobrar ética de uma organização quando os parâmetros para avaliação dessa conduta referem-se a escolhas e capacidades de discernimento de indivíduos, e não de coletividades? E mais: como definir o certo e o errado, o bom e o mau, o justo e o injusto, diante do argumento dos relativistas éticos, segundo os quais as definições de cada grupo e contexto, mesmo antagônicas, são igualmente legítimas?

Algumas perguntas não precisam de respostas rápidas, justamente porque o seu valor reside na capacidade de gerar inquietações e deslocamentos. Somos parte desses errantes e, diante da primeira pergunta, seguimos a trilha de José Antônio Puppim de Oliveira (2008, p. 78), segundo o qual a ética de uma empresa é observável num conjunto de fatores e condutas: "os princípios usados em sua estrutura de tomada de decisão e ação, que inclui gestores e normas sociais e corporativas”.

Para as duas questões, percorremos ainda, com curiosidade e simpatia, trilhas de Jürgen Habermas (1989, p. 1), em um artigo no qual ele analisa a pergunta "Como devo comportar-me?”. Segundo o autor, essa é a questão que tanto a ética moderna quanto 
a clássica apresenta ao indivíduo quando ele "encontra-se diante de uma tarefa a ser vencida de maneira prática”. Adiante, Habermas (op. cit., p. 5) afirma que, "dependendo de como o problema se põe, a questão 'que devo fazer?' ganha um significado pragmático, ético ou moral", requerendo respostas pautadas pelo que é "eficiente", pelo que é "bom" e pelo que é "justo", respectivamente.

As variantes da questão habermasiana estão situadas no campo da razão prática e exigem raciocínios e discernimentos diferenciados: questões pragmáticas pedem uma solução orientada ao atendimento de uma meta; questões éticas não podem prescindir de uma reflexão a respeito do que seria bom para a pessoa não apenas imediatamente, mas a médio e longo prazo; já a decisão sobre um assunto do interesse de uma coletividade pede uma resposta ainda mais complexa e que possa ser qualificada como uma máxima justa, isto é, aquela diante da qual "todos os envolvidos podem querer que ela seja seguida por cada um em situações comparáveis" (ibid, p. 5).

Com base nos autores e obras citadas, a resposta provisória para as nossas questões de partida, e para poder seguir refletindo, é... sim! É procedente fazer julgamentos de empresas sob o ponto de vista ético. E, mais: é oportuno questionar as condutas empresariais do ponto de vista da moralidade pública, isto é, indagando pelo viés do que é justo nas ações e omissões por elas praticadas.

Isso significa interessar-se pela inteligência dos gestores (ética - capacidade de discernimento a pequeno, médio e longo prazo sobre o que é bom para a empresa) e pela eficácia do setor produtivo no enfrentamento dos problemas sociais dos ambientes nos quais as empresas estão situadas (moralidade pública - capacidade de tomar atitudes justas, segundo a máxima há pouco citada).

\section{Do absolutismo do lucro ao complexo da sustentabilidade}

Um ponto vulnerável das empresas que desejam ser reconhecidas como sendo social e ambientalmente responsáveis é a sua forma de produzir riqueza. A atuação nas regras, sempre em criação, da responsabilidade social exige um comprometimento das empresas com o estabelecimento e a manutenção de uma estrutura de gestão da qual o lucro é consequência, como refletem Marcelo Orchis, Maurício Yung e Santiago Morales (2002, p. 41), citando Levitt:

"Dizer que o lucro é o propósito da empresa é simplesmente e moralmente vazio. Quem, com dignidade e um mínimo de sensibilidade, defenderia o direito de alguém conseguir lucro, apenas pelo lucro? Se não puder ser discernido ou justificado um objetivo maior, a empresa não pode justificar moralmente sua existência. Essa é uma idéia repugnante, uma idéia cujo tempo já passou."

Está cada vez menos defensável a idéia da atuação de uma empresa cujo foco seja apenas o interesses dos acionistas, como defendia o ganhador do Nobel em Economia, Milton Friedman, segundo o qual a única responsabilidade social das empresas é 
"gerar lucros para seus acionistas, dentro das regras da sociedade" (OLIVEIRA, 2008, p. 67). Na atualidade, esse pensamento é criticado quanto ao foco (gerar lucro), à direção (para seus acionistas) e à forma (dentro das regras da sociedade).

Os conceitos de desenvolvimento sustentável, stakeholders e responsabilidade social empresarial condicionam a moralidade do lucro ao equivalente desenvolvimento social e ambiental; à partilha desses lucros com todas as partes interessadas da empresa; e, finalmente, à atuação e participação das empresas no enfrentamento dos problemas sociais não apenas para cumprir a lei (que é uma obrigação), mas por decisão voluntária.

Essa ampliação da responsabilidade das empresas deriva do enfraquecimento do conceito de separação rígida entre Estado, Economia e Sociedade. Em artigo sobre a iniciativa privada e o interesse público, com base na teoria de Edward Lorentz, Wilson da Costa Bueno (2007, p. 130) fala do chamado "efeito borboleta", segundo o qual todas as coisas estão interligadas e qualquer intervenção altera o equilíbrio do todo.

A atuação de empresas impacta, positiva ou negativamente, os ecossistemas e interfere na organização da sociedade, no funcionamento da economia e nos demais aspectos da vida. Analisando o cenário da economia mundial, Oliveira (op. cit., p. 3) afirma que, em 2005, 100 empresas estavam entre as 150 maiores entidades em termos econômicos. E completa: "A cadeia de lojas Wal-Mart já era a $22^{\mathrm{a}}$ entidade do mundo, seguida pelas gigantes do petróleo, como a BP, Esso e Shell, com receitas que ultrapassam o PIB de países como Portugal, Grécia e Finlândia”.

Proporcional ao porte é o potencial de impacto dessas empresas, portanto, é justo que a sociedade espere e exija delas cuidados e atuação para com o todo social em que estão inseridas, e não apenas direcionados aos seus próprios cofres. Nesse contexto, muitos autores do campo da administração atualmente falam da necessidade do estabelecimento de um paradigma de sustentação das atividades produtivas que não se reduza à análise do desempenho econômico.

Entre os pensadores dessa corrente está o sociólogo britânico John Elkington que, em 1995, cunhou a expressão Triple Bottom Line, o chamado tripé da sustentabilidade (COUTO, 2006, p. 22). Segundo ele, o desempenho das empresas passa a depender da capacidade de seus administradores equilibrarem, de modo dinâmico, as dimensões social (garantia da independência das comunidades locais, atendimento das necessidades humanas básicas, justiça, participação e uso de tecnologia apropriada), ambiental (capacidade de condução dos negócios, aliando produtividade, conservação de recursos e da biodiversidade) e econômica (crescimento econômico, lucro particular, expansão dos negócios e externalização dos custos), expressas na ilustração a seguir.

A interconexão das dimensões social, ambiental e econômica como definidora de uma atividade econômica sustentável ou de uma empresa socioambientalmente 


\section{Dimensão Econômica}

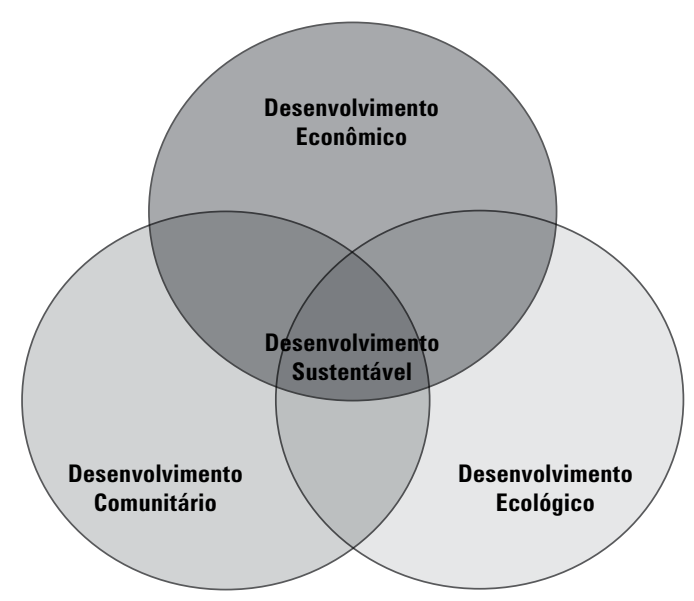

Dimensão Social

Dimensão Ambiental

Adaptado de Pereira (2005, p. 28).

responsável aponta importante mudança no modo de produção capitalista na perspectiva do reconhecimento dos direitos humanos, direitos trabalhistas e outros tantos, já de há muito consagrados em convenções internacionais, porém ainda com poucos resultados palpáveis no cotidiano de uma parcela significativa da humanidade.

São procedentes, porém, as advertências de Luciana Miotto (2005) a respeito do "desenvolvimento sustentável”, termo central do Relatório Brundtland, de 1987, produzido pela Comissão Mundial sobre Meio Ambiente (ONU), e que, segundo ela, pode ser apenas um "capitalismo verde" ou uma adequação de tecnologias e de formas de acumulação capitalista às circunstâncias contemporâneas. Coerência entre o que se diz e o que se pratica nas empresas é o que sugere e cobra Miotto:

"O desenvolvimento sustentável deve propor mudanças reais, pois não se trata apenas de rever a racionalidade econômica. É necessário um projeto de sociedade que atenda às necessidades humanas e, necessariamente, isso implica adentrar o campo da ética e dos valores de uma sociedade." (op. cit., p. 85)

Isso quer dizer que, para ter a credibilidade, o discurso do desenvolvimento sustentável e da responsabilidade social precisa ter base numa prática e numa conduta efetivamente sustentáveis e que a gestão da imagem seja o instrumento de apresentar à sociedade o que realmente aquela organização é, como reflete Hannah Arendt (1987, p. 192) a respeito da publicidade requerida na chamada ação política: "Na ação e no 
discurso, os homens mostram quem são, revelam ativamente suas identidades pessoais e singulares, e assim apresentam-se ao mundo humano". A coerência entre ação e discurso é prerrogativa tanto para pessoas públicas quanto para organizações de qualquer natureza. Saber com quem estamos lidando é um direito que assiste a toda pessoa cidadã, participante de uma sociedade verdadeiramente democrática.

\section{Responsabilidade socioambiental: um conceito em elaboração}

Num inventário sobre o conceito de responsabilidade social, Oliveira (op. cit., p. 72) recorda o pensamento da Comissão Européia, que o aplica a empresas que "integram de forma voluntária preocupações sociais e ambientais nas suas operações empresariais e na sua interação com as partes interessadas", e a elaboração do Banco Mundial, que define responsabilidade social corporativa como o

"compromisso das empresas em contribuir para o desenvolvimento econômico sustentável através do trabalho com os empregados, suas familias, a comunidade local e a sociedade como um todo a fim de melhorar suas vidas de maneira que seja bom para os negócios e para o desenvolvimento."

A principal afirmação do autor, nesse contexto, é que não há unanimidade em torno do termo e que, portanto, responsabilidade social empresarial é um conceito em elaboração.

A definição que adotamos no presente artigo é dada pelo Instituto Ethos (2008):

"Responsabilidade social empresarial é a forma de gestão que se define pela relação ética e transparente da empresa com todos os públicos com os quais ela se relaciona e pelo estabelecimento de metas empresariais compatíveis com o desenvolvimento sustentável da sociedade, preservando recursos ambientais e culturais para as gerações futuras, respeitando a diversidade e promovendo a redução das desigualdades sociais."

Atualmente, há uma enorme quantidade de prêmios, instrumentos e ferramentas de gestão em responsabilidade social, disponíveis para empresas e organizações de qualquer ramo ou porte. Um desses instrumentos são os Indicadores Ethos de Responsabilidade Social Empresarial, que correlacionam, de modo integrado, "iniciativas relevantes como o Pacto Global, os Objetivos do Milênio, as diretrizes do relatório de sustentabilidade da Global Reporting Initiative (GRI), a Norma SA8000" (MELO \& MOYA, 2007, p. 9), bem como o Índice de Desenvolvimento Infantil Empresarial (Ethos e Unicef) e o Balanço Social (Ibase).

Ao todo, os Indicadores Ethos apresentam um conjunto de mais de 600 questões, num volume de 82 páginas, organizado em sete temas: Valores, Transparência e Governança; Público interno; Meio ambiente; Fornecedores; Consumidores e Clientes; Comunidade; Governo e Sociedade.

Embora a quantidade de perguntas não seja suficiente para determinar o peso de um tema na avaliação de desempenho de uma organização, chama a atenção o fato de o 
tema "Público Interno" dos Indicadores Ethos reunir praticamente a metade de todas as questões apresentadas por essa ferramenta, como ilustra o gráfico a seguir:

\section{Gráfico 1. Quantidade de questões por tema dos Indicadores Ethos de Responsabilidade Social Empresarial 2007}

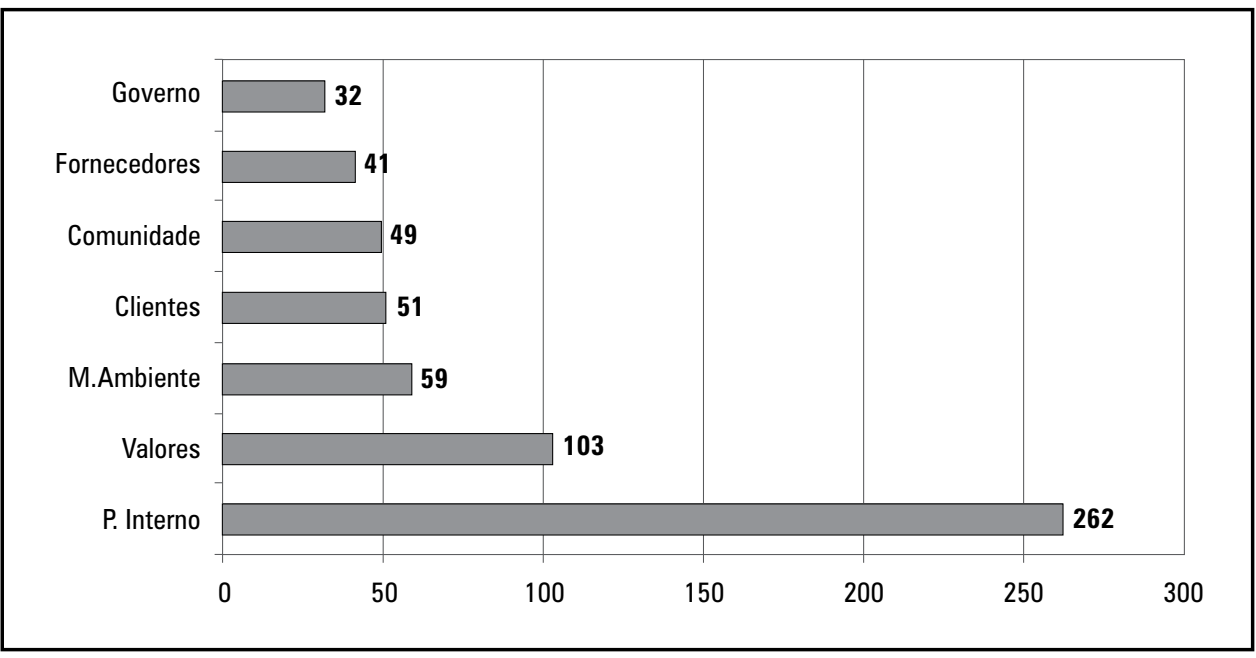

Esses dados fazem pensar no descompasso que há entre o que o senso comum enxerga como indício de responsabilidade social empresarial e aquilo que compõe os critérios dos estudiosos do tema. Quando se fala nesse assunto, nove em cada dez pessoas pensam nas doações ou nos projetos sociais que as empresas financiam. Talvez esse pensamento tenha origem na prática de empresas nada responsáveis que costumam gastar em campanhas publicitárias de sua "ação social" dez vezes mais do que tudo o que investem na atividade-fim. Dessa forma, essas empresas customizam velhas práticas assistencialistas que, mesmo quando têm motivação nobre, são incapazes de transformar a realidade com a qual estão lidando; geram dependência ao invés de autonomia e, assim, agravam os problemas que deveriam contribuir para superar.

Esse tipo de projeto deveria ser entendido como filantropia empresarial, como os analisa o Instituto Ethos ${ }^{1}$, definindo-os como ação isolada e externa, enquanto responsabilidade social

"é focada na cadeia de negócios da empresa e engloba preocupações com um público maior [...] cuja demanda e necessidade a empresa deve buscar entender e incorporar aos negócios. Assim, a responsabilidade social trata diretamente dos negócios da empresa e de como ela os conduz".

1 Disponível em: http://www.ethos.org.br. Acesso em: 9 de jan. de 2008. 
E concordamos mais integralmente ainda com a afirmação de Wilson da Costa Bueno: "Ações pontuais, aparentemente de interesse público, são realizadas mesmo por traficantes de drogas e políticos corruptos e, ao fechar o foco, pode-se contribuir para legitimar posturas ilegitimas e que escondem as verdadeiras e nefastas intenções de quem as realiza. "(op. cit., p. 139)

Além dos atos isolados, ainda desafiam as empresas que declaram interesse em ser reconhecidas como socioambientalmente responsáveis certos paradoxos que resultam do confronto entre suas boas intenções e os produtos que efetivamente aportam para a sociedade e para o mundo. Qual a responsabilidade socioambiental possível para empresas que ganham cifras astronômicas oferecendo produtos que causam danos irreparáveis às pessoas e ao planeta? Quantos milhões a Fundação Souza Cruz precisará investir em projetos sociais para compensar as mortes causadas pelo fumo que ela produz e dispõe, sedutoramente, para a sociedade?

\section{Para onde caminha a responsabilidade social?}

Se ainda não há consensos sobre o que é responsabilidade social empresarial, pelo menos há certa unanimidade que esse conceito refere-se à totalidade da conduta de uma organização do setor produtivo, e não a ações isoladas. O passo seguinte na evolução desse conceito também já nos parece esboçado e tem a ver com a exigência de interação social como mecanismo definidor das práticas e da imagem pública das empresas que pretendem ser reconhecidas como sócio e ambientalmente responsáveis.

Um dos mecanismos mais relevantes do relatório de sustentabilidade da Global Reporting Initiative, por exemplo, é a especificação de quando e como foi o envolvimento de segmentos das partes interessadas participantes do processo de elaboração do relatório. Dessa forma, não é um colegiado de especialistas nem uma organização certificadora que avaliza o relatório de uma empresa, mas os seus empregados, as comunidades da região, ONGs, representantes de órgãos públicos, clientes, fornecedores, a mídia e outras pessoas e grupos afetados e que tenham sido ouvidas no processo de discussão e deliberação a respeito do desempenho da empresa em termos econômicos sociais e ambientais.

No conjunto de questões apresentado pelos Indicadores Ethos de Responsabilidade Social 2007 também há um grupo significativo de questões que conduzem as empresas a adotar uma postura de transparência ou prestação de contas das suas atividades para a sociedade na qual estão inseridas. Um exemplo: "A empresa fornece aos consumidores e clientes informações detalhadas sobre danos ambientais resultantes do uso e da destinação final de seus produtos?” (CUSTÓDIO \& MOYA, 2007, p. 43).

Esse conjunto de quesitos indaga sobre a publicação do balanço social, sobre a informação dos empregados a respeito de medidas que afetam a sua vida, sobre a realização de campanhas informativas internas em torno de temas como a equidade racial, entre outros. Embora seja altamente recomendada, a efetivação dessas práticas de- 
pende inteiramente da decisão da empresa ou de seus gestores, devido ao seu caráter unidirecional, e, portanto, a sua implementação não garante a escuta ou a participação dos supostos beneficiários.

Há um outro grupo de questões, entretanto, para cuja efetivação é imprescindível que se estabeleça diálogo da empresa com outros segmentos sociais, criando esferas públicas para discussão de assuntos que envolvam aqueles que se sentem parte dos públicos de interesse de uma empresa ou que se sentem afetados por suas ações. $O$ grupo tem 48 questões, distribuídas nos sete temas dos Indicadores Ethos de Responsabilidade Social Empresarial, como mostra o gráfico a seguir:

Gráfico 2. Quantidade de questões por tema dos Indicadores Ethos de Responsabilidade Social Empresarial 2007

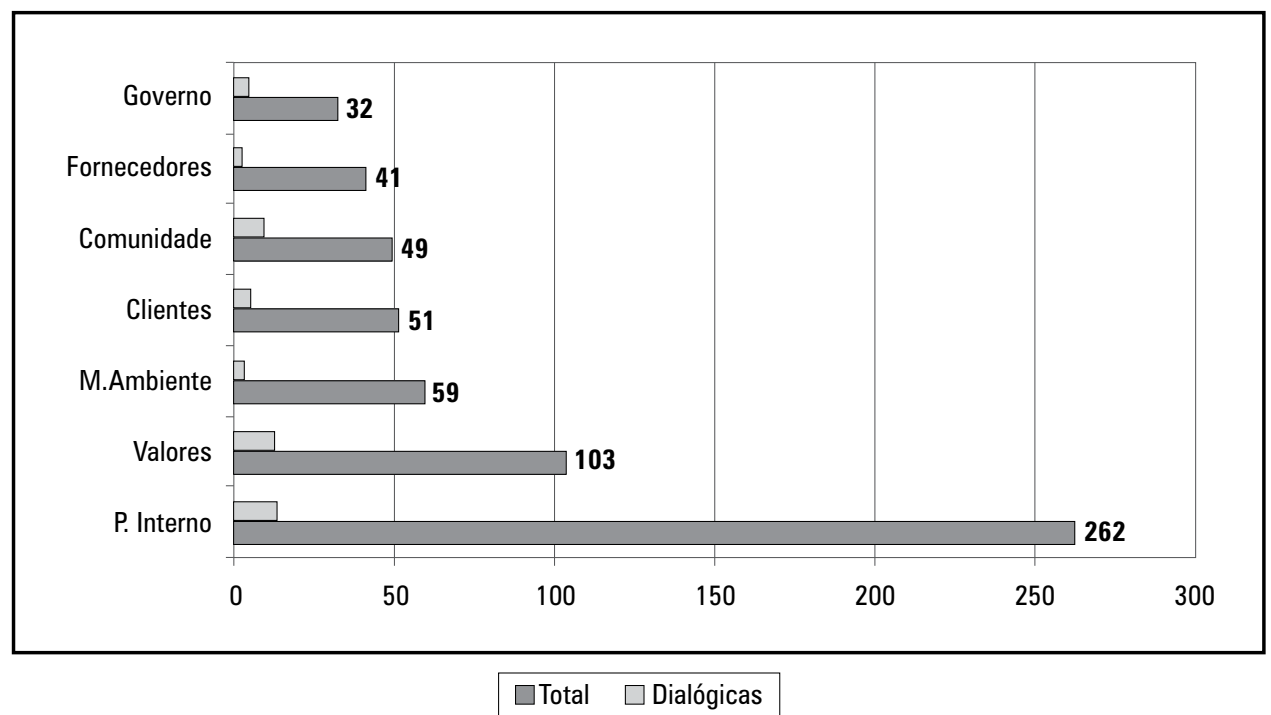

Para conhecer a natureza dessas questões, vejamos alguns exemplos (CUSTÓDIO \& MOYA, op. cit., itens $6.3 ; 6,4 ; 18,3)$, com grifos nossos:

"No processo de elaboração do balanço social, a empresa envolve pelo menos quatro das seguintes partes interessadas: comunidade, público interno, consumidores, clientes, fornecedores, governo e sociedade em geral (por meio, por exemplo, de contatos com organizações de defesa do meio ambiente, sindicatos, entidades voltadas para a saúde pública ou defesa dos direitos humanos etc.)?"

"A empresa incorpora no balanço social críticas, sugestões e depoimentos de partes interessadas?"

"A empresa busca estabelecer diálogo estruturado com instâncias do governo local, especialistas, ONGs e sindicatos para conhecer, entender, prever e reduzir o impacto de um possivel fechamento de unidades de negócio ou plantas, ou da eventual necessidade de corte de pessoal?" 
O envolvimento de distintos setores, a incorporação de críticas e sugestões vindas desses grupos, o estabelecimento de diálogo estruturado e não episódico são, a nosso ver, o mais exigente e elevado nível de comprometimento de uma empresa com os propósitos de ser sócio e ambientalmente responsável. Se as questões informativas dependem da lisura da empresa e, portanto, estão sujeitas à manipulação, essa vulnerabilidade se reduz drasticamente quando responsabilidade social deixar de ser assunto "privado" e passar a integrar a pauta dos temas de interesse público. Assim como a violência doméstica migrou do espaço interno da casa (oikos) para a praça (polis), a ética e a moralidade por parte das empresas também devem ser politizadas, de modo que responsabilidade social não seja mais uma espécie de opcional de luxo e passe a pré-requisito das atividades produtivas.

\section{Considerações finais}

Os instrumentais disponíveis para balizar os estudos ou práticas de responsabilidade social empresarial são abundantes e bastante qualificados para fazer avançar a moralidade pública na condução dos negócios ditos privados ou a função social inerente aos serviços prestados pela iniciativa privada. Nem quantidade, nem qualidade dos instrumentos disponíveis, entretanto, garantem a adoção de práticas social e ambientalmente responsáveis por parte da maioria das empresas, nem promovem a necessária sinergia entre as organizações de todas as naturezas para o enfrentamento dos problemas sociais que afetam a coletividade.

Mesmo a pressão da concorrência do mercado capitalista global é insuficiente para promover esse alinhamento das empresas às novas filosofias administrativas, uma vez que há grande espaço de manobra no campo da gestão da imagem, pelo uso das ferramentas do marketing especializado em produzir essa espécie de ilusionismo que faz ver o desejável e que, efetivamente, não existe.

A consistência do discurso da responsabilidade social empresarial depende, em grande medida, de que este se torne um tema de interesse público, fazendo que a boa ou má conduta das empresas torne-se ponto de pauta das esferas públicas constituídas por administradores, funcionários, fornecedores, comunidades, organizações ambientais e todos aqueles que constituem os públicos afetados por determinada atividade empresarial. $\mathrm{O}$ acompanhamento atento, qualificado e perene da sociedade civil para com as atividades das empresas aumenta a possibilidade de que essas organizações cumpram as suas obrigações econômicas, legais e éticas, além de fazê-las entender que somente a adesão irrestrita aos parâmetros da responsabilidade social e ambiental é que poderá firmar a sua reputação junto a seus públicos de interesse.

\section{Referências}

ARENDT, Hannah. A condição humana. Rio de Janeiro: Forense-Universitária, 1987.

BUENO, Wilson da Costa. Comunicação, iniciativa privada e interesse público. In: DUARTE, Jorge (Org.). Comunicação pública: estado, governo, mercado, sociedade e interesse público. São Paulo: Atlas, 2007. 
COUTO, Renan Evangelista. Turismo como mecanismo de desenvolvimento local e empreendedorismo sustentável: análise da demanda e do espaço rural do alto Aiuruoca, Itamonte, MG. 2006. 102f. Dissertação (Mestrado em Engenharia de Produção), UFF, Niterói, 2006.

CUSTÓDIO, Ana Lúcia de Melo e MOYA, Renato (Coord.). Guia para Elaboração de Balanço Social e Relatório de Sustentabilidade 2007. São Paulo: Instituto Ethos, 2007.

FEDATO, Maria Cristina Lopes. Responsabilidade social corporativa: benefício social ou vantagem competitiva? Um estudo das estratégias de atuação social empresarial e sua avaliação de resultados. 2005. 142 f. Dissertação (Mestrado em Administração), USP, São Paulo, 2005.

HABERMAS, Jürgen. Para uso pragmático, ético e moral da razão prática. Estudos Avançados, Vol. 3, nº 7. São Paulo, set/dez, 1989.

INSTITUTO ETHOS. Disponível em: http://www.ethos.org.br/DesktopDefault.aspx?TabID=3344\&Alias=Ethos\&Lang=pt-BR. Acesso em 20 de ago. de 2008.

MELO, Ana Lúcia de \& MOYA, Renato (Coord. da revisão 2007). Indicadores Ethos de Responsabilidade Social Empresarial 2007. São Paulo: Instituto Ethos, 2007.

MIOTTO, Luciana Bernardo. A ecoeficiência e a responsabilidade socioambiental das empresas. In: BEZZON, Lara Andréa Crivelaro (Org.). Comunicação, política e sociedade. Campinas: Editora Alínea, 2005.

OLIVEIRA, José Antônio Puppim de. Empresas na sociedade: sustentabilidade e responsabilidade social. Rio de Janeiro: Elsevier, 2008.

ORCHIS, Marcelo A.; YUNG, Maurício T.; e MORALES, Santiago C. Impactos da responsabilidade social nos objetivos e estratégias empresariais. In: Responsabilidade social das empresas - a contrapartida das universidades. São Paulo: Ed. Fundação Peirópolis, 2002.

PEREIRA, Luís Felipe Ramos. Aspectos conceituais da ecoeficiência no contexto do desenvolvimento sustentável. 2005. $78 f$. Dissertação (Mestrado em Sistema de Gestão). UFF, Niterói, 2005. 


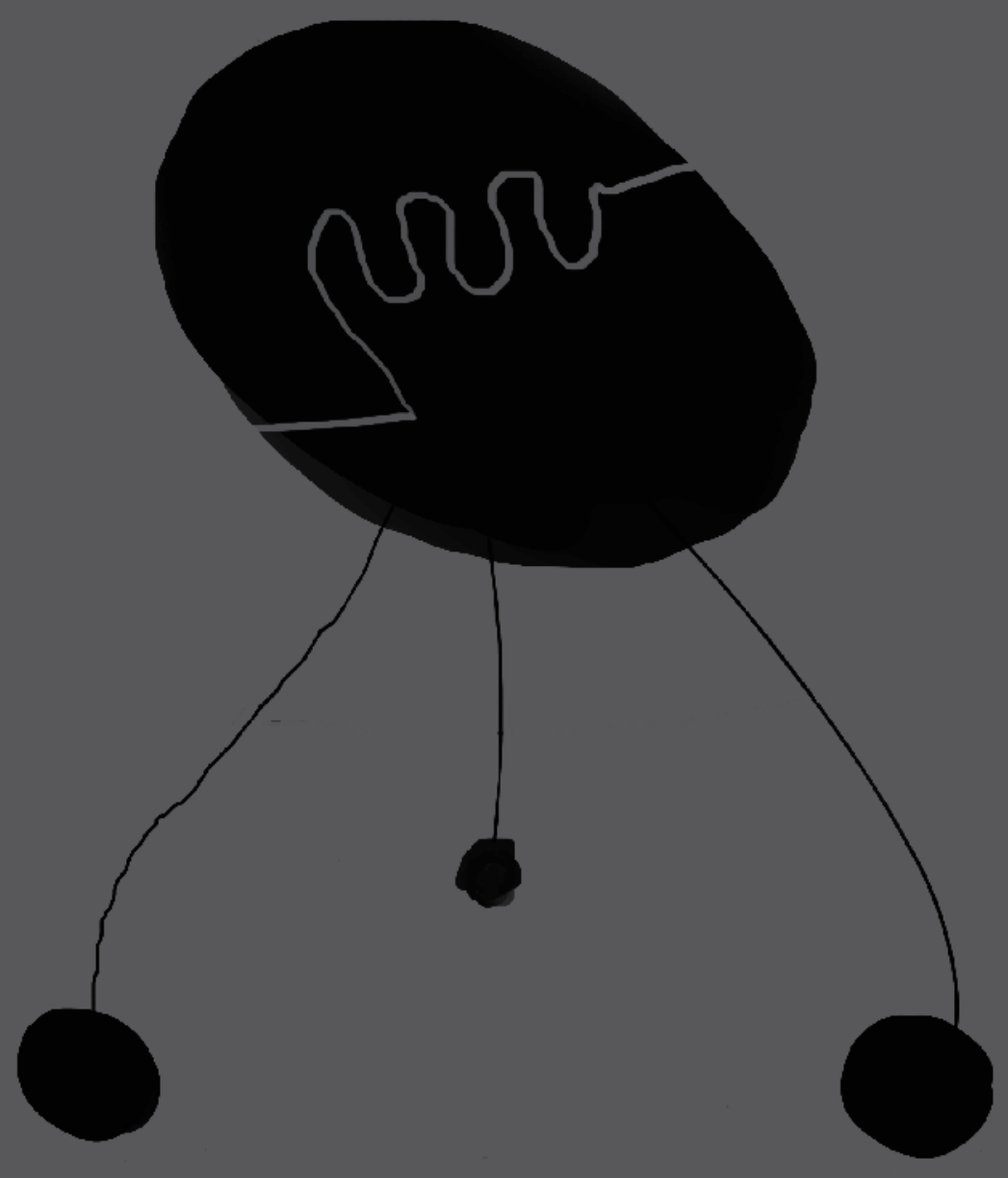

